\title{
Synthesis of 3-Isopropylbenzo[D]Oxazol-2(3H)-One Amides and Urea Derivatives; Evaluation of their Anti-Mycobacterial and Cytotoxic Activity
} Indrasena Reddy $\mathrm{K}^{1^{*}}$, Aruna $\mathrm{C}^{1}$, Padma Sridevi J², Yogeeswari $\mathrm{P}^{2}$, Sriram $\mathrm{D}^{2}$ and Vijayakumar $\mathbf{V}^{3}$

${ }^{1}$ Department of Chemistry, Sri Krishnadevaraya University, Anantapur, Andhra Pradesh, India

${ }^{2}$ Birla Institute of Technology and Science, Pilani, Hyderabad Campus, Telangana, India

${ }^{3}$ Centre for Organic and Medicinal Chemistry, VIT University, Vellore, Tamil Nadu, India

\begin{abstract}
Tuberculosis (TB) is a traditional disease caused by infection with Mycobacterium tuberculosis, it is a serious public health issue due to its risk of person-to-person transmission, and high level of morbidity and humanity. The World Health Organization (WHO) estimates 11.4 million people worldwide are infected with both Mycobacterium tuberculosis (Mtb) and HIV. Currently, there are approximately 8 million new infections and 3 million deaths attributed to M. tuberculosis annually. One of the major problems associated in comprehensive control of TB is that the restart of the disease in patients who carry a latent syndrome, in which the bacteria is in slow budding or non growing state and is refractory to treat with predictable anti-TB drugs. Directly observed treatment (DOT) is presently practicing for standard TB chemotherapy. It is well known that the resistance levels are poor in the areas with a strongly performing DOTS programmes. However, various drugs available in the market cannot be used for prolonged times due to diverse side effects. Therefore, the development of new and safe anti-TB drugs is in high demand. The major investigation on SEH inhibitors focused on urea, amide, amino- heterocycles and carbamate derivatives, but research on new compound structures is limited. Benzoxazolones are widely distributed in plants and are of increasing interest for a variety of pharmacological properties, such as detoxification, antibacterial, antiHIV, anti-inflammatory, and transequilizers. Since benzoxazolones are active and inexpensive, many structural modification and preliminary bioactivity evaluation studies have been performed based on benzoxazol-ones. In this paper, 3-isopropyl benzo[d]oxazol-2(3H)-one amides and urea analogues were synthesized and evaluated as sEH inhibitors in vitro, and their anti-tuberculosis activities were determined in vivo. The 3-isopropylbenzo[d]oxazol$2(3 \mathrm{H})$-one heterocycles has received considerable attention from the medicinal chemists owing to their capacity to mimic a benzamides or a phenyl urea moiety in a metabolically stable template. This class of compounds has led to the discovery of a number of derivatives endowed with antibacterial-antifungal, analgesic-antiinflammatory, anticonvulsant, dopaminergic, HIV-1 reverse transcriptase activity, and normolipenic agents. Usually functionalization of the nitrogen atom is of interest, since the electronic characteristic of this atom can be decisive for the biological activity. Nevertheless, most efforts have focused on N-, 5-, or 6-substituted benzoxazol-ones. Presently, 5-substituted benzoxazolone derivatives have been scarcely prepared, and few reports have described the sEH inhibitory activities or anti-tuberculosis activities. The pronounced biological activity of benzoxazolone derivatives and the lack of structure-bioactivity relationships prompted our investigation on 5-substituted-3isopropylbenzo[d]oxazol-2(3H)-one.
\end{abstract}

Keywords: Mycobacterium tuberculosis; Anti-mycobacterial; HIV; Cytotoxic

\section{Introduction}

As part of our research on biologically active heterocycles, 23 we herein reported an efficient method for the synthesis of 3 -isopropylbenzo[d]oxazol-2(3H)-one amides and phenyl urea analogues. It is known that estrification is an important method for structural modification [1-15]. Hence, benzoate and besilate, the most common modified groups, were introduced to optimize the skeleton structure 2(3H)-benzoxazolones at 5-position (Tables 1 and 2 ). The synthetic route is outlined in Scheme 1. The starting material 2 -amino-4-bromophenol 1 was reacted with ethyl $1 \mathrm{H}$-imidazole-1carboxylate under a nitrogen atmosphere in THF reflux to provide 5-bromobenzo[d]oxazol-2(3H)-one 2, which reacted with isopropyl iodide to afford the corresponding 5-bromo-3-isopropylbenzo[d] oxazol-2(3H)-ones 3 . This compound 3 was underwent suzuki crosscoupling reaction with 3 -aminophenylboronic acid in $\mathrm{Pd}(\mathrm{II}) \mathrm{Cl} 2$ (dppf) and $\mathrm{K} 2 \mathrm{CO} 3$ offered compound 4 [16-24]. The 4-bromo benzoyl chloride reacted with compound 4 yield the compound 5 in good yield. The compound 5 reacted with 2 -amino phenyl boronic acid provide scaffold 6 . The coupling reaction carried out with compound 6 and different acid chlorides obtained amide $7 \mathrm{a}-\mathrm{n}$ in excellent yields (Scheme 1). Corresponding urea derivatives in good yields (Scheme 2).
The general, practical and established method was successfully applied for the synthesis of 3-isopropylbenzo[d] oxazol-2(3H)-one amides 7a-n and urea derivatives $8 \mathrm{a}-\mathrm{d}$. Thus synthesized compounds $7 \mathrm{a}-\mathrm{n}$ and $8 \mathrm{a}-\mathrm{d}$ are well characterized by spectral data. These 3-isopropylbenzo[d] oxazol-2(3H)-one amides $7 \mathrm{a}-\mathrm{n}$ and urea derivatives $8 \mathrm{a}-\mathrm{d}$ were screened for their anti-mycobacterial activity [25-29].

\section{In Vitro Anti-Mycobacterial Activity}

Compound 6 reacts with various phenyl, pyrazole, pyridine and cyclobutyl acid chlorides or isocyanates were synthesized 3-isopropylbenzo[d]oxazol-2(3H)-one amides $7 \mathrm{a}-\mathrm{n}$ and urea derivatives $8 \mathrm{a}-\mathrm{d}$. The synthesized compounds were screened for their

*Corresponding author: Indrasena Reddy K, Department of Chemistry, Sr Krishnadevaraya University, Anantapur-515 055, Andhra Pradesh, India, Tel: 8582813194; E-mail: indra111sena@gmail.com

Received May 05, 2017; Accepted May 27, 2017; Published May 31, 2017

Citation: Indrasena Reddy K, Aruna C, Padma Sridevi J, Yogeeswari P, Sriram D, et al. (2017) Synthesis of 3-Isopropylbenzo[D]Oxazol-2(3H)-One Amides and Urea Derivatives; Evaluation of their Anti-Mycobacterial and Cytotoxic Activity. Med Chem (Los Angeles) 7: 904-907. doi: 10.4172/2161-0444.1000451

Copyright: (ㄷ 2017 Indrasena Reddy K, et al. This is an open-access article distributed under the terms of the Creative Commons Attribution License, which permits unrestricted use, distribution, and reproduction in any medium, provided the original author and source are credited. 
Citation: Indrasena Reddy K, Aruna C, Padma Sridevi J, Yogeeswari P, Sriram D, et al. (2017) Synthesis of 3-Isopropylbenzo[D]Oxazol-2(3H)-One Amides and Urea Derivatives; Evaluation of their Anti-Mycobacterial and Cytotoxic Activity. Med Chem (Los Angeles) 7: 904-907. doi: 10.4172/2161-0444.1000451

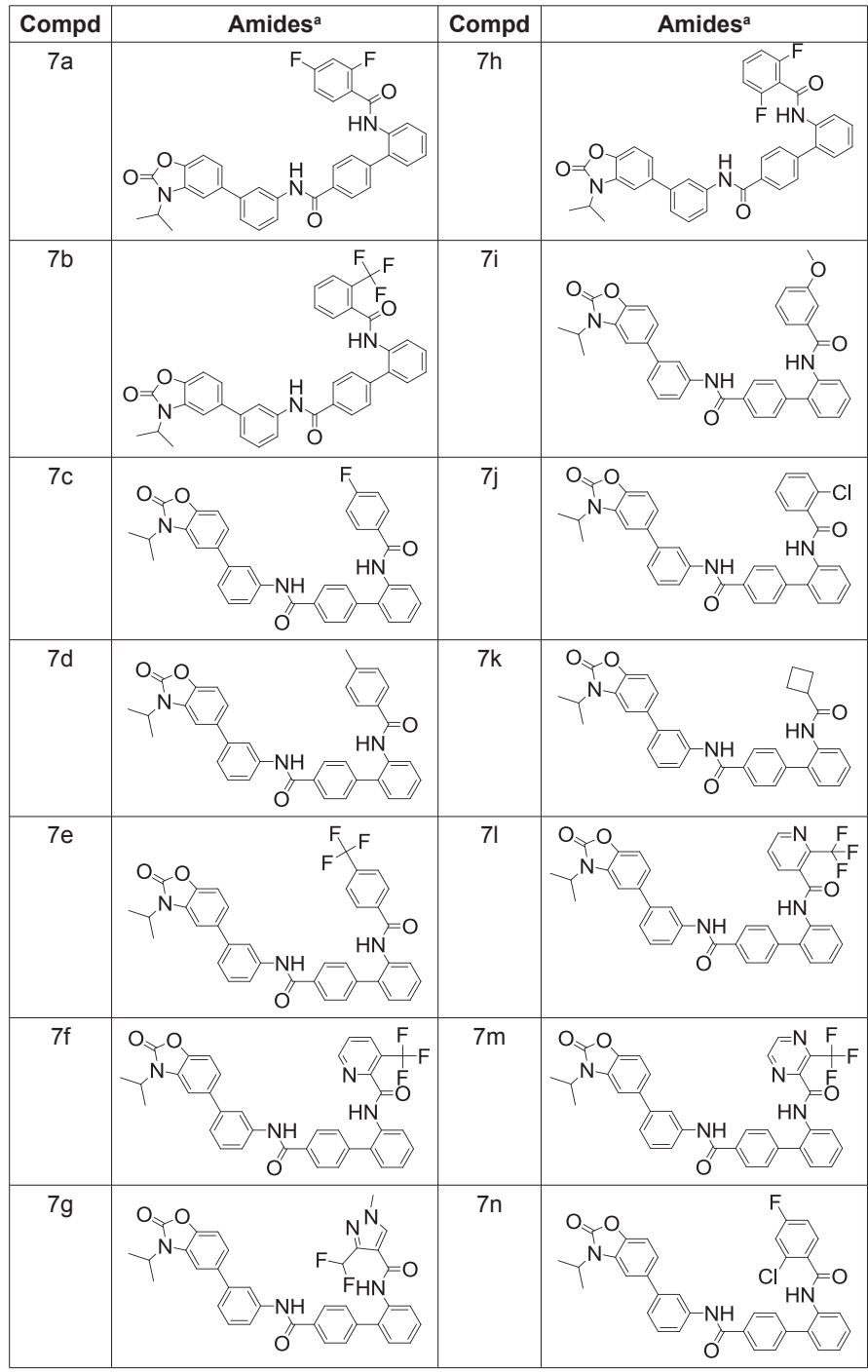

aAll products were characterized by NMR, IR and mass spectrometry.

Table 1: Synthesis of 3-isopropylbenzo[d]oxazol-2(3H)-one amide derivatives (7a-n).

in vitro anti-mycobacterial activity against M. tuberculosis H37Rv (MTB) by agar dilution method recommended by National Committee for Clinical Laboratory Standards for the determination of MIC and the values of the synthesized compounds along with standard drugs Isoniazid, Ethambutol and Ciprofloxacin for comparison are presented in Table 3. Based on MIC values we could observe structure-activity relationship by the influence of substituted amides and urea derivatives. Anti-mycobacterial screening of $7 \mathrm{a}-\mathrm{n}$ and $8 \mathrm{a}-\mathrm{d}$ reveals that all the tested compounds showed moderate to good activity against the tested antimycobacterial assay and MIC's ranging from 1.56 to $50.0 \mu \mathrm{g} / \mathrm{mL}$. The compound $8 \mathrm{a}$ showed excellent activity against anti-mycobacteria same as Ethambutol (MIC=1.56). The compounds $7 \mathrm{a}, 7 \mathrm{e}, 7 \mathrm{f}, 7 \mathrm{~g}, 8 \mathrm{c}$, and $8 \mathrm{~d}$ showed good activity. Unfortunately, the compounds $7 \mathrm{~d}, 7 \mathrm{j}, 7 \mathrm{k}, 7 \mathrm{l}$ and $8 \mathrm{~b}$ showed poor anti-mycobacterial activity against $8 \mathrm{a}$. The activity of the 4-CF3 compound 7e, 3-(trifluoromethyl) picolinamide compound $7 \mathrm{f}$ and $8 \mathrm{c}$ were same $(\mathrm{MIC}=6.5)$ potent against both replicating and non-replicating $M$. tuberculosis. When the $4-\mathrm{CF} 3$ in the compound $7 \mathrm{e}$ and $7 \mathrm{f}$ with $\mathrm{MIC}=6.5$ was replace with $2-\mathrm{CF} 3$ group of compound $7 \mathrm{~b}$ with a MIC of 25, was 4 -fold less active. All experiments were carried out in triplicates and the results were reported as \pm SD. From the antimycobacterial activity, the MIC values are calculated and presented in

Compd

${ }^{a}$ All products were characterized by NMR, IR and mass spectrometry.

Table 2: Synthesis of 3-isopropylbenzo[d]oxazol-2(3H)-one urea derivatives (8a-d).

Table 3. The values presented in the Table 3 suggested that electronic effect may play a role in the anti-tuberculosis activity in this series.

\section{Cytotoxic Evaluation}

All the synthesized compounds $7 \mathrm{a}-\mathrm{n}$ and $8 \mathrm{a}-\mathrm{d}$ were subjected to WST-1 cytotoxicity assay against Panc-1 (human pancreatic adenocarcinoma) and H460 (human non-small cell lung carcinoma) cell lines. These compounds were inactive towards to cytotoxicity against both the cancer cell lines tested, hence the \% cytotoxicity at various concentrations of the compounds were obtained and the respective IC50 value for the corresponding cell lines were obtained through the plot.

\section{Conclusions}

In summary, we have developed a simple method for the synthesis of 3-isopropylbenzo[d]oxazol-2(3H)-one amides $7 \mathrm{a}-\mathrm{n}$ and urea $8 \mathrm{a}-\mathrm{d}$ derivatives. The suzuki coupling reaction of boronic acid with bromo benzene in the presence of $\mathrm{Pd}(\mathrm{II})$ catalyst under reflux conditions provides the novel class of amide and urea derivatives which are found to possess interesting anti-micobactirial properties. This method also describes the synthesis of benzoxazol moiety which is found to possess interesting anti-mycobacterial properties.

\section{General}

All chemicals used possess a purity of $>95 \%$. Yields refers to pure products after purification and are unoptimized. Melting points were determined in open capillaries on Gallenkamp apparatus and are uncorrected. Microanalyses were conducted on Perkin-Elmer 240C or Perkin-Elmer Series II CHNS/O Analyzer 2400 instrument. Silica gel 60 (230-400 mesh) was used for the column chromatography. TLC plates (Silica Gel 60 F254) were used for thin-layer chromatography (TLC). Aluminum oxide (activity II-III), Brockmann grade was used. 

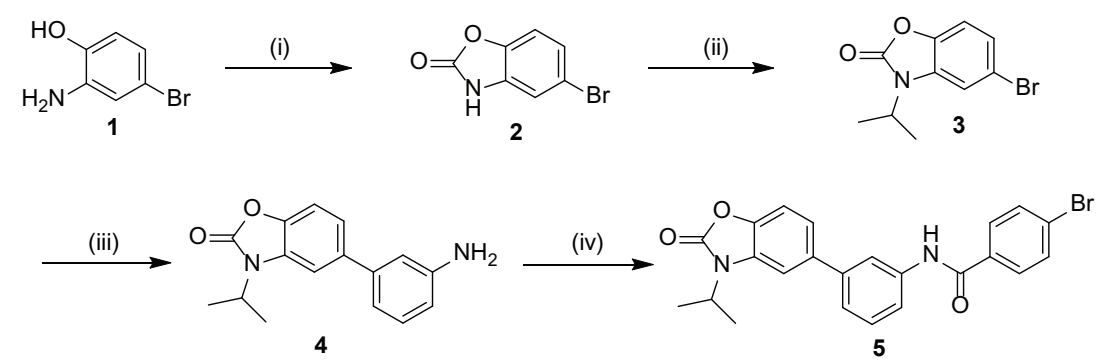

(v)
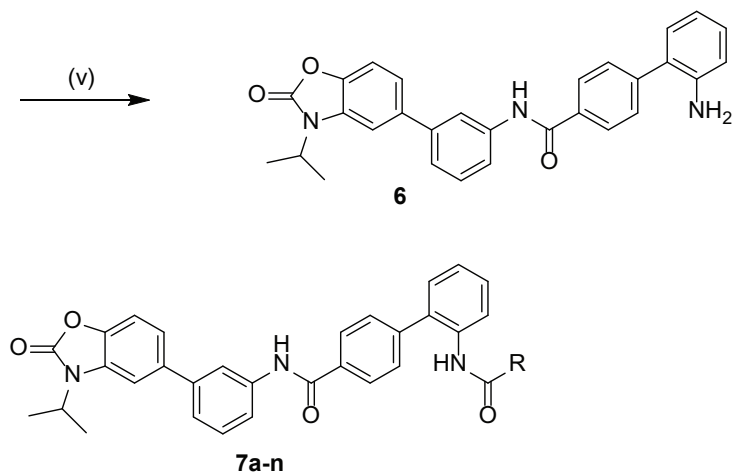

Scheme 1: Reagents and conditions. (i) ethyl $1 \mathrm{H}$-imidazole-1-carboxylate, $\mathrm{THF}, 70^{\circ} \mathrm{C}, 12 \mathrm{~h}$; (ii) Isopropyl iodide, $\mathrm{K} 2 \mathrm{CO} 3, \mathrm{THF}, 70^{\circ} \mathrm{C}, 12 \mathrm{~h}$; (iii) $\mathrm{Pd}(\mathrm{II}) \mathrm{Cl} 2$ (dppf), K2CO3, Boronic acid, EtOH+Toluene, reflux; iv) 4-bromo benzoyl Chloride, DCM, 2h, RT; (v) Pd(11)Cl2(dppf), K2CO3, Boronic acid, EtOH+Toluene, reflux; (vi). $\mathrm{RCOCl}, \mathrm{DCM}, 2 \mathrm{~h}, \mathrm{RT}$.
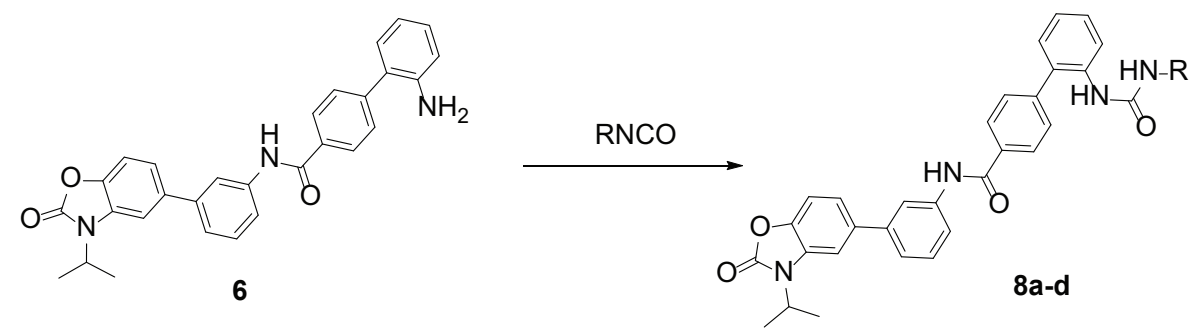

Scheme 2: Reagent and conditions. (i) RNCO, DCM, RT.

\begin{tabular}{|c|c|c|c|c|}
\hline Entry & Compd & CLogPa & MIC $(\mu \mathbf{g} / \mathbf{m l})$ & MIC $(\mu \mathbf{m})$ \\
\hline 1 & $7 \mathrm{a}$ & 5.83 & 25 & 48.28 \\
\hline 2 & $7 \mathrm{~b}$ & 5.73 & 25 & 25.42 \\
\hline 3 & $7 \mathrm{c}$ & 6.04 & 50 & 23.42 \\
\hline 4 & $7 \mathrm{~d}$ & 6.24 & 6.25 & 11.63 \\
\hline 5 & $7 \mathrm{e}$ & 6.94 & 125 & 1.70 \\
\hline 6 & $7 \mathrm{f}$ & 5.06 & 25 & 49.73 \\
\hline 7 & $7 \mathrm{~g}$ & 4.08 & 25 & 24.14 \\
\hline 8 & $7 \mathrm{~h}$ & 5.42 & 50 & 23.90 \\
\hline 9 & $7 \mathrm{i}$ & 5.90 & 50 & 12.04 \\
\hline 10 & $7 \mathrm{j}$ & 5.78 & 50 & 10.91 \\
\hline 11 & $7 \mathrm{k}$ & 5.16 & 25 & 12.73 \\
\hline 12 & $7 \mathrm{~m}$ & 4.71 & 25 & 25.48 \\
\hline 13 & $7 \mathrm{n}$ & 4.20 & 1.56 & 24.76 \\
\hline 14 & $7 \mathrm{p}$ & 5.98 & 50 & 350.39 \\
\hline 15 & $7 \mathrm{p}$ & 6.00 & 7.09 & \\
\hline
\end{tabular}

Table 3: Anti-mycobacterial activity of 7a-n and 8a-d against Mycobacterium smegmatis. 
Citation: Indrasena Reddy K, Aruna C, Padma Sridevi J, Yogeeswari P, Sriram D, et al. (2017) Synthesis of 3-Isopropylbenzo[D]Oxazol-2(3H)-One Amides and Urea Derivatives; Evaluation of their Anti-Mycobacterial and Cytotoxic Activity. Med Chem (Los Angeles) 7: 904-907. doi: $10.4172 / 2161-0444.1000451$

\section{Experimental procedure:}

1. General procedure for the synthesis of substituted Benzoxazolidine-one amides (7a-n): The compound 6 react with benzoyl chlorides in $\mathrm{CH} 2 \mathrm{Cl} 2$ as a solvent for $2 \mathrm{~h}$ at RT. Upon completion, the solvent was removed under reduced pressure and the residue was purified by column chromatography to produce substituted benzoxazolidine-one amides.

2. General procedure for the synthesis of substituted Benzoxazolidine-one urea derivatives (8a-d): The compound 6 react with isocyanates in $\mathrm{CH} 2 \mathrm{Cl} 2$ as a solvent for $2 \mathrm{~h}$ at $\mathrm{RT}$. Upon completion, the solvent was removed under reduced pressure and the residue was purified by column chromatography to afford benzoxazolidine-one urea derivatives.

\section{Supplementary Data}

Supplementary data contains spectral data of compounds $7 \mathrm{a}-\mathrm{n}$ (Table 1) and 8a-d (Table 2).

\section{References}

1. Maher D, Raviglione M (2005) Global epidemiology of tuberculosis. Clinics in Chest Medicine 26: 167-182.

2. World Health Organization (2004) Global Tuberculosis Control: SurVeillance, Planning, Financing. WHO Report 2004: Geneva, Switzerland.

3. Cegielski JP, Chin DP, Espinal MA, Frieden TR, Cruz RR, et al. (2002) The global tuberculosis situation: progress and problems in the 20th century, prospects for the 21st century. Infectious Disease Clinics of North America 16: $1-58$.

4. Wood AJJ, Iseman MD (1993) New England Journal of Medicine 329: 784.

5. Farmer $\mathrm{P}$ (2001) The major infectious diseases in the world-to treat or not to treat?.

6. Frieden TR, Munsiff SS (2005) The DOTS strategy for controlling the global tuberculosis epidemic. Clinics in Chest Medicine 26: 197-205.

7. Renuka J, Reddy KI, Srihari K, Jeankumar VU, Shravan M, (2014) Design synthesis, biological evaluation of substituted benzofurans as DNA gyraseB inhibitors of Mycobacterium tuberculosis. Bioorganic \& Medicinal Chemistry 22: 4924-4934.

8. Idhayadhulla A, Kumar RS, Nasser AJ (2011) Synthesis, characterization and antimicrobial activity of new pyrrole derivatives. Journal of the Mexican and antimicrobial activity of new

9. Reddy KI, Aruna C, Babu KS, Vijayakumar V, Manisha M, et al. (2014) General and efficient synthesis of benzoxazol-2 (3 H)-ones: evolution of their anticancer and anti-mycobacterial activities. RSC Advances 4: 59594-59602.

10. Ucar H, Depovere P, Lesieur D, Isa M, Masereel B, et al. (1998) "Fries like" rearrangement: A novel and efficient method for the synthesis of 6-acyl-2 (3H)benzoxazolones and 6-acyl-2 (3H)-benzothiazolones. Tetrahedron 54: 1763 1772.

11. Fu Y, Baba T, Ono $Y$ (197) Carbonylation of o-phenylenediamine and o-aminophenol with dimethyl carbonate using lead compounds as catalysts. Journal of Catalysis 197: 91-97.

12. Gulcan HO, Kupeli E, Unlu S, Yesilada E, Sahin MF (2003) 4-(5-Chloro-2 (3H)benzoxazolon-3-yl) Butanoic Acid Derivatives: Synthesis, Antinociceptive and Anti-inflammatory Properties. Archiv der Pharmazie 336: 477-482.

13. Shankaran K, Donnelly KL, Shah SK, Humes JL, Pacholok SG, et al. (1997) Inhibition of nitric oxide synthase by benzoxazolones. Bioorganic \& Medicinal Chemistry Letters 7: 2887-2892.

14. Penning TD, Khilevich A, Chen BB, Russell MA, Boys ML, et al. (2006) Synthesis of pyrazoles and isoxazoles as potent $\alpha \vee \beta 3$ receptor antagonists. Bioorganic \& Medicinal Chemistry Letters 16: 3156-3161.

15. Reddy KI, Aruna C, Manisha M, Srihari K, Babu KS, et al. (2017) Synthesis, DNA binding and in-vitro cytotoxicity studies on novel bis-pyrazoles. Journal of Photochemistry and Photobiology B: Biology 168: 89-97.

16. Daidone G, Maggio B, Raffa D, Plescia S, Schillaci D, et al. (2004) Synthesis and in vitro antileukemic activity of new 4-triazenopyrazole derivatives. II Farmaco 59: 413-417.

17. Veeraswamy S, Reddy KI, Ragavan RV, Yennam S, Jayashree A (2013) Ethyl
Imidazole-1-carboxylate (EImC) as a Carbonylating Agent: Efficient Synthesis of Oxazolidin-2-ones from Amino Alcohols. Chemistry Letters 42: 109-111.

18. Manetti F, Brullo C, Magnani M, Mosci F, Chelli B, et al. (2008) Structurebased optimization of pyrazolo [3, 4-d] pyrimidines as Abl inhibitors and antiproliferative agents toward human leukemia cell lines. Journal of Medicinal Chemistry 51: 1252-1259.

19. Mohammed I, Kummetha IR, Singh G, Sharova N, Lichinchi G, et al. (2016) 1 2, 3-Triazoles as Amide Bioisosteres: Discovery of a New Class of Potent HIV-1 Vif Antagonists. Journal of Medicinal Chemistry 59: 7677-7682.

20. Xia Y, Dong ZW, Zhao BX, Ge X, Meng N, et al. (2007) Synthesis and structure-activity relationships of novel 1-arylmethyl-3-aryl-1H-pyrazole-5carbohydrazide derivatives as potential agents against A549 lung cancer cells. Bioorganic \& Medicinal Chemistry 15: 6893-6899.

21. Xia Y, Fan CD, Zhao BX, Zhao J, Shin DS, et al. (2008) Synthesis and structure-activity relationships of novel 1-arylmethyl-3-aryl-1H-pyrazole-5 carbohydrazide hydrazone derivatives as potential agents against A549 lung cancer cells. European Journal of Medicinal Chemistry 43: 2347-2353.

22. Farag AM, Mayhoub AS, Barakat SE, Bayomi AH (2008) Regioselective synthesis and antitumor screening of some novel $\mathrm{N}$-phenylpyrazole derivatives. Bioorganic \& Medicinal Chemistry 16: 881-889.

23. Reddy KI, Srihari K, Renuka J, Sree KS, Chuppala A, et al. (2014) An efficient synthesis and biological screening of benzofuran and benzo [d] isothiazole derivatives for Mycobacterium tuberculosis DNA GyrB inhibition. Bioorganic \& Medicinal Chemistry 22: 6552-6563.

24. Mullen G, Napier J, Balestra M, DeCory T, Hale G, et al. (2000) (-)-Spiro [1-azabicyclo [2.2. 2] octane-3, 5 '-oxazolidin-2 '-one], a Conformationally Restricted Analogue of Acetylcholine, Is a Highly Selective Full Agonist at the a7 Nicotinic Acetylcholine Receptor. Journal of Medicinal Chemistry 43: 40454050 .

25. Veeraswamy S, Reddy KI, Ragavan RV, Reddy KT, Yennam S, et al. (2012) An efficient one-step chemoselective reduction of alkyl ketones over aryl ketones in $\beta$-diketones using LiHMDS and lithium aluminium hydride. Tetrahedron Letters 53: 4651-4653.

26. Van Kampen M, Selbach K, Schneider R, Schiegel E, Boess F, et al. (2004) AR-R 17779 improves social recognition in rats by activation of nicotinic a7 receptors. Psychopharmacology 172: 375-383.

27. Li Z, Zhan P, Naesens L, Vanderlinden E, Liu A, et al. (2012) Synthesis and Preliminary Biologic Evaluation of 5-Substituted-2-(4-substituted phenyl)-1, 3-Benzoxazoles as A Novel Class of Influenza Virus A Inhibitors. Chemical Biology \& Drug Design 79: 1018-1024.

28. Kunz KR, Taylor EW, Hutton HM, Blackburn BJ (1990) Organic Preparations and Procedures International: The New Journal for Organic Synthesis 22: 613.

29. Reddy BS, Reddy MR, Madan CH, Kumar KP, Rao MS (2010) Indium (III) chloride catalyzed three-component coupling reaction: A novel synthesis of 2-substituted aryl (indolyl) kojic acid derivatives as potent antifungal and antibacterial agents. Bioorganic \& Medicinal Chemistry Letters 20: 7507-7511. 